\title{
Postpartum Seizures: Cerebral Venous Sinus Thrombosis, Case Report
}

\author{
Ahmed AAH* \\ Medical Intern at Wad Medani Teaching Hospital, Sudan \\ *Corresponding author: Asim Ahmed Hussein \\ Ahmed, Medical Intern at Wad Medani Teaching \\ Hospital, Wad Medani, Gezira State, Sudan
}

Received: February 05, 2021; Accepted: February 25, 2021; Published: March 04, 2021

\begin{abstract}
Cerebral venous sinus thrombosis is of rarity during pregnancy, and it is included in the differential diagnosis of a woman presenting with seizures during pregnancy and puerperium. Here we report a case of young lady who developed Cerebral Venous Sinus Thrombosis (CVST) 6 days after delivery, presented with a chief complain of loss of consciousness and high grade fever with recent past history of severe occipital headache and generalized convulsions, which progressed into left sided weakness. Magnetic Resonance Imaging (MRI) / Magnetic Resonance Venography (MRV) demonstrated filling defects at the right transverse and sigmoid sinuses. The patient was started on Enoxaparin and warfarin. The patient kept on improving gradually and was discharged after 24 days in a good condition.
\end{abstract}

Keywords: Postpartum; Venous thrombosis; Cerebral; Seizures; Case report; Pregnancy; Puerperium

\section{Introduction}

Cerebral venous sinus thrombosis is a rarely encountered condition during pregnancy, however, pregnancy itself, puerperium, coagulopathies, cerebral infections, malignancies, dehydration and the Pill are amongst its commonest causes [1,2]. Signs and symptoms of the disease include headache, blurring of vision, focal and/or generalized convulsions and papilledema [1-3].

\section{Case Presentation}

25 years old, house wife, Para 2 delivered by emergency cesarean section due to 1 previous scar in labour on top of major degree contracted pelvis on $14^{\text {th }}$ of July 2019 . The outcome was a $3.2 \mathrm{~kg}$ male baby, now alive and well. Both pregnancy and delivery were without complications. She was referred to Wad Medani Obstetrics and Gynecology hospital, Gezira state, Sudan on 22nd of July 2019 with a chief complain of loss of consciousness and high grade continuous fever 6 days postoperatively. The condition was preceded by generalized tonic clonic seizures, thrice, not preceded by aura after which the patient was postictal and lost her sphincters control. The relatives reported a history of severe occipital headache not relieved by over-the-counter paracetamol. They denied a history of blurred vision and projectile vomiting. They also denied a past history of epilepsy.

Physical examination revealed a comatose woman with a Glasgow Coma Scale (GCS) of 8/15, not pale, jaundiced or cyanosed. Vital signs were: pulse 90 beats/min, blood pressure 130/80 mmHg, respiratory rate $30 \mathrm{cycle} / \mathrm{min}$ and a temperature of 37.9 degree Celsius. Cardiovascular system and abdominal examination was normal, the wound site was clean and intact. Chest examination revealed dullness on percussion and coarse crepitation all over the chest. Neurological examination showed hypotonia and hyporeflexia in both upper limbs, and the lower limbs were dorsi-flexed and laterally rotated and both hypotonic and hyporeflexic. Power, sensation and coordination were difficult to be assessed.
Baseline routine investigations were requested including (Table 1): Blood film for malaria: negative, hemoglobin level: $10.8 \mathrm{~g} / \mathrm{dl}$, platelet count $269^{*} 103$, white cell count: $9.3^{*} 103$, random blood glucose $121 \mathrm{mg} / \mathrm{dl}$, renal function test: blood urea $9.9 \mathrm{mmol} / \mathrm{l}$, serum creatinine $0.5 \mathrm{mmol} / \mathrm{l}$, coagulation profile: International Normalized Ratio (INR) 1.3, Prothrombin Time (PT) 17 seconds, liver function test came normal, urine analysis was clear except for $6-8$ pus cells/ HPF and uncountable red blood cells. Computed Tomography (CT) was done which showed hyper-dense superior sagittal sinus features that are suggestive of Venous Sinus Thrombosis (VST) and advised further imaging studies (Figure 1). Magnetic Resonance Imaging (MRI) showed high signal intensity at the right occipital area, features that are suggestive of cerebral infarcts (Figure 2). Magnetic Resonance Venography (MRV) revealed a filling defect at the right transverse and sigmoid sinuses and the right internal jugular vein is not opacified, features that are suggestive of venous thrombosis (Figure 3 ). The final impression was a right cerebral infarct and right sinus thrombosis. The patient was admitted to the High Dependency Unit (HDU), a nasogastric tube was fixed with $300 \mathrm{ml}$ feed every 4 hours and a fluid maintenance of $500 \mathrm{ml}$ every 8 hours with dextrose in normal saline. The patient was covered by injectable antibiotics (ceftriaxone $1 \mathrm{~g}$ IV BID and metronidazole 500mg drip TDS) proton pump inhibitors (pantoprazole 40mg IV) and paracetamol 500mg drip BID. The patient was also started on phenytoin loading ( 3 ampules in $500 \mathrm{ml}$ normal saline drip over 24 hours) and maintenance doses ( 1 ampule in $500 \mathrm{ml}$ every 8 hours) and dexamethasone $10 \mathrm{mg}$ BID. Next day the patient was started on Enoxaparin $6000 \mathrm{IU}$ subcutaneously twice a day and Aspirin 300mg Once Daily (OD) through the NG tube for 3 days then replaced by clopidogrel $75 \mathrm{mg}$ OD. Five days following admission, the patient started to regain her consciousness and was found to have left sided weakness. She was discharged after 24 days in good condition (GCS 15) and oral warfarin $5 \mathrm{mg}$ OD (INR 1.3). She was able to control over her sphincters and able to walk with support. Then one month after discharge, warfarin dose was reduced to $3 \mathrm{mg}$ OD according to the INR result (INR 2.3). 


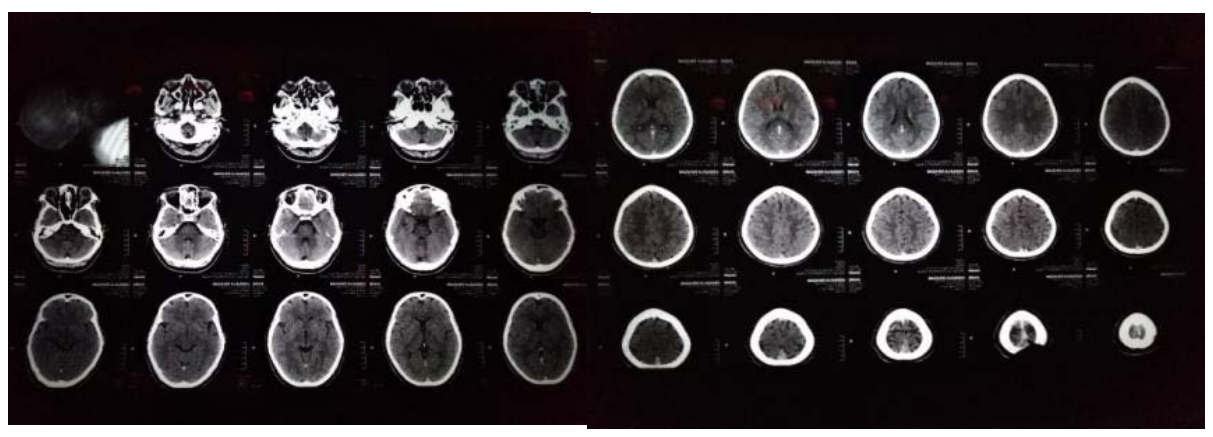

Figure 1: A non-contrast computed tomography (CT) scan shows hyper-density of the superior sagittal sinus; note the arrows.

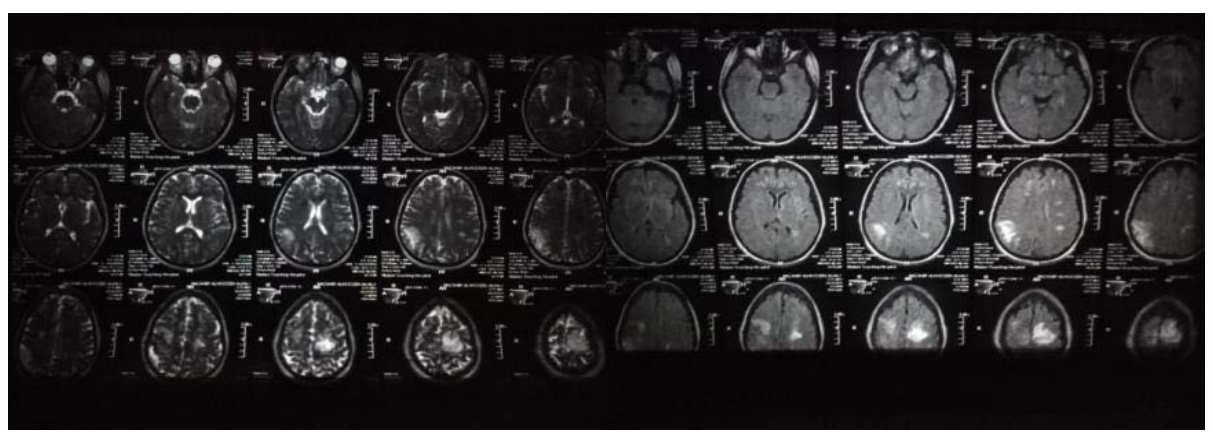

Figure 2: Magnetic Resonance imaging (MRI) of the brain, shows high signal intensity at the right occipital area, suggestive of right cerebral infarct. Note the arrows.

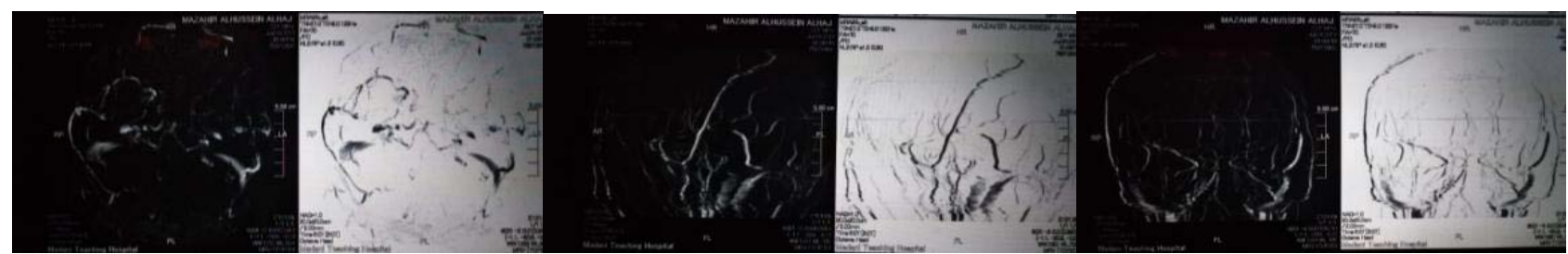

Figure 3: Magnetic Resonance Venography (MRV) of the brain, shows filling defects at the right transverse and sigmoid sinus features of venous thrombosis. Note the arrows.

\section{Discussion}

Globally the incidence of CVST is about $0.5 \%$ to $1 \%$, which is way much less when compared to its incidence in Sudan, which is about $6.6 \%$ to $7.3 \%$ [4]. it mainly affect the young subjects; particularly females in reproductive age, owing to the risk factors that they might have i.e. pregnancy, puerperium and the use of oral contraceptive pills [5]. So when a pregnant or a postpartum female -as in the case of our patient-presents with focal neurologic deficits, headache and seizure, it is of great significance to assess her for CVST risk.

The diagnosis of CVST can be quite challenging as it can present with symptoms that mimic many neurological conditions [3]. The diagnosis of CVST should be considered in any woman presenting with any neurological symptoms during pregnancy or puerperium. These symptoms include severe headache which is often localized rather than diffuse, seizures, visual changes and paresis/paralysis $[2,6]$. Our patient presented with a recent history of generalized tonic-clonic convulsions and sub-acute severe occipital headache, then progressed to coma and paralysis. As stated in the literature, convulsions are mainly of focal type, but life threatening generalized tonic-clonic convulsions have been also reported [1].

The clinical features and the time of presentation for a patient with CVST mostly depends on the degree of involvement of the cerebral veins and collateral venous formation. Ranging from a slowly progressive to an acute process [4].

Neuroimaging remains the best diagnostic tool for CVST with variable sensitivity and specificity. CT scans are usually obtained in the initial workup and are suggestive but inconclusive in diagnosing CVST and mostly an additional imaging would be required [1-3,57]. Magnetic resonance imaging and magnetic resonance venography are both sensitive and specific methods of diagnosing CVST $[2,3,7,8]$. However, it is not routinely used unless endovascular thrombolysis is employed; Angiography is considered a gold standard invasive diagnostic and therapeutic method for CVST (not available in our case).

The treatment for CVST is still controversial; however anticoagulation with heparin then followed by long-term warfarin 
Table 1: Lab results and imaging studies.

\begin{tabular}{|c|c|c|}
\hline Test & Date & Results \\
\hline $\begin{array}{l}\text { Blood film for } \\
\text { malaria }\end{array}$ & $22 / 7 / 2019$ & Negative \\
\hline \multirow{2}{*}{$\begin{array}{l}\text { Coagulation } \\
\text { profile }\end{array}$} & \multirow{2}{*}{$22 / 7 / 2019$} & PT 17 seconds \\
\hline & & INR 1.3 \\
\hline RBS & $22 / 7 / 2019$ & $121 \mathrm{~g} / \mathrm{dl}$ \\
\hline \multirow{2}{*}{ RFT } & \multirow{2}{*}{$22 / 7 / 2019$} & BUN $9.9 \mathrm{mmol} / \mathrm{l}$ \\
\hline & & Serum creat. $0.5 \mathrm{mmol} / \mathrm{l}$ \\
\hline LFT & $22 / 7 / 2019$ & All parameters are within normal range \\
\hline CT brain & $22 / 7 / 2019$ & $\begin{array}{l}\text { Figure 1: hyper-dense superior sagittal sinus, } \\
\text { MRI/MRV is advised }\end{array}$ \\
\hline \multirow{2}{*}{ Urine analysis } & \multirow{2}{*}{$23 / 7 / 2019$} & Pus cells $6-8 / \mathrm{HPF}$ \\
\hline & & RBCs uncountable \\
\hline MRI/MRV & $25 / 7 / 2019$ & Figure 2 \\
\hline \multirow{2}{*}{ Urine analysis } & \multirow{2}{*}{ 30/7/2019 } & Pus cells $5-7 / \mathrm{HPF}$ \\
\hline & & RBCs 12-14/HPF \\
\hline \multirow{2}{*}{$\begin{array}{l}\text { Coagulation } \\
\text { profile }\end{array}$} & \multirow{2}{*}{$30 / 7 / 2019$} & PT 26 seconds \\
\hline & & INR 1.8 \\
\hline \multirow{3}{*}{$\begin{array}{l}\text { Coagulation } \\
\text { profile }\end{array}$} & \multirow{3}{*}{$04 / 08 / 2019$} & PT 17 seconds \\
\hline & & PTT 33 seconds \\
\hline & & INR 1.3 \\
\hline
\end{tabular}

i.e. 3 to 6 months, remains the best treatment option as stated by the European Federation of Neurological Societies guidelines [1-3,5,7,8]. They should be offered anticoagulation regardless the duration of symptoms, the severity of the neurological deficit and whether there is an intracranial hemorrhage or not [5]. Symptomatic treatment should be started as well; including anticonvulsants, strong analgesia.

This case emphasizes the importance of preserving a broad differential diagnosis in women presenting with postpartum seizure. Although eclampsia is the most reasonable cause, other rare conditions, may be responsible. It also suggests that the time of presentation and intervention could be associated with the clinical outcome, which was excellent in our patient.

\section{Conclusion}

The case described in the this report is of a young nursing lady with no past history of chronic illnesses, presented 6 days post-delivery with loss of consciousness and high grade fever and with a recent history of severe headache and convulsions, diagnosed as Cerebral Venous Sinus Thrombosis, particularly the right sinus. The patient received anticoagulation (Enoxaparin and warfarin), improved dramatically over a short period of time and was discharged in a good condition.

\section{Ethical Consideration and Consent}

A verbal informed consent was obtained from the patient for publication of this case report and the accompanying images.

\section{Author(s) Contribution}

Asim Ahmed Hussein Ahmed: participated in concepts, literature search, data acquisition, manuscript preparation and editing and final approval of the version to be published.

\section{References}

1. Soydinc HE, Ozler A, Evsen MS, Sak ME, Turgut A, Basaranoglu S, et al. A Case of Cerebral Sinus Venous Thrombosis Resulting in Mortality in Severe Preeclamptic Pregnant Woman. Case Rep Obstet Gynecol. 2013; 2013.

2. Delashaw MR, Vizioli TL, Counselman FL. Clinical Communications: $\mathrm{Ob}$ Gyn Headache and Seizure in a Young Woman Postpartum. The Journal of Emergency Medicine. 2005; 29: 289-293.

3. Han KH, Won YD, Na MK, Han M-H, Ryu JI, Kim JM, et al. Postpartum Superior Sagittal Sinus Thrombosis: A Case Report. Korean J Neurotrauma 2018; 14: 146-149.

4. Abu O, Seidi A. Cerebral Venous Sinus Thrombosis Among Sudanese Patients in the Term of Clinical Presentation, Risk Factor \& Outcome. Ejbps. 2019; 6: 93-106.

5. Idris M-N, Sokrab T-E, Ibrahim EA, Mirgani SM, Elzibair MA, Osman RR et al. Cerebral venous thrombosis Clinical presentation and outcome in a prospective series from Sudan. Neurosciences. 2008; 13: 408-411.

6. Anand N, Chan C, Wang NE. Clinical Communications: Adults Cerebra Venous Thrombosis: A Case ReporT. JEM. 2009; 36: 132-137.

7. Wittmann M, Dewald D, Urbach H, Gast A-S, Linnebank M, Baumgarten $\mathrm{G}$, et al. Sinus venous thrombosis: a diVerential diagnosis of postpartum headache. Arch Gynecol Obs. 2012; 285: 93-97.

8. Kashkoush Al, Ma H, Agarwal N, Panczykowski D, Tonetti D, Weiner GM, et al. Cerebral venous sinus thrombosis in pregnancy and puerperium: A pooled, systematic review. 2017; 39: 9-15. 